\title{
AS RELAÇÕES DE GÊNERO NO INÍCIO DO SOCIALISMO CHINÊS: REFLEXÕES A PARTIR DOS CARTAZES DE PROPAGANDA DO I PLANO QUINQUENAL (1953-1957)
}

\author{
Edelson Costa Parnov ${ }^{1}$ \\ Tatiana Silva Poggi de Figueiredo ${ }^{2}$
}

\begin{abstract}
Resumo: Este artigo tem como objetivo elucidar as funções e os usos relacionados às representações de gênero dos cartazes de propaganda chineses do I Plano Quinquenal (1953-7). As fontes estão disponíveis no site http://chineseposters.net/, mantido pela Leiden University. Ele reúne pôsteres da coleção de Stefan Landsberger, professor emérito dessa instituição, e de uma coleção particular anônima. Utilizou-se o método iconológico para a análise imagética e a Análise Crítica do Discurso para o estudo das legendas dos cartazes. Defende-se que o Partido Comunista usou os pôsteres para construir hegemonia na sociedade chinesa acerca das relações de gênero consideradas em acordo com o socialismo, valorizando modelos de mulheres ativas no mundo do trabalho e de casais harmoniosos. Com isso, esses sujeitos não transportariam seus problemas pessoais para a esfera da produção, possibilitando o seu incremento, fator tido como fundamental à transição socialista.
\end{abstract}

Palavras-chave: China. Gênero. Plano quinquenal. Revolução chinesa. Socialismo.

\section{THE GENDER RELATIONS AR THE BEGINNING OF CHINESE SOCIALISM: REFLECTIONS THE PROPAGANDA POSTERS OF THE FIRST FIVE-YEAR PLAN (1953-1597)}

\begin{abstract}
This article aims to elucidate the functions and uses related to gender representations of the Chinese propaganda posters of the First Five-Year Plan (1953-7). The sources are available at http://chineseposters.net/ maintained by Leiden University. It collects posters from the collection of Stefan Landsberger, emeritus teacher of this institution, and from an anonymous private collection. It was used the iconological method to analyze the images and Critical Discourse Analysis for the study of poster subtitles. It is argued that the Communist Party used the posters to build hegemony in Chinese society over gender relations considered in accordance with socialism, valuing models of women active in the working world and harmonious couples, that would not carry their problems into the sphere of production,. production sphere, enabling its increase, a factor considered fundamental to the socialist transition.
\end{abstract}

Keywords: China. Gender. Five-year plan. Chinese revolution. Socialism.

\section{LES RELATIONS DE GENRE AU DÉBUT DU SOCIALISME CHINOIS : RÉFLEXIONS TIRÉES DES AFFICHES DE PROPAGANDE DU PREMIER PLAN QUINQUENNAL (1953-1957)}

Résumé: Le But de cet article est élucider les fonctions et les utilisations liées aux représentations de genre des affiches de propagande chinoise du Premier Plan Quinquennal

\footnotetext{
1 Mestrando em História do Programa de Pós-Graduação em História da Universidade Federal Fluminense (PPGH/UFF), com bolsa da Coordenação de Aperfeiçoamento de Pessoal de Nível Superior (CAPES). Atua como pesquisador do Centro de Estudos Asiáticos (CEA) da UFF e pesquisador associado do Laboratório de Estudos da Ásia da Universidade de São Paulo (LEA/USP); integrante da Associação Nacional de História (ANPUH), da Rede Brasileira de Estudos da China (RBChina) e da Asociación Latinoamericana de Estudios de Asia y África (ALADAA). E-mail: ecparnov@gmail.com.

2 Professora de História Contemporânea na Universidade Federal Fluminense. Possui graduação em História pela Universidade Federal Fluminense (2004), mestrado (2008) e doutorado (2012) pela Universidade Federal Fluminense. E-mail: tatiana.poggi@gmail.com.
}

Revista Escritas do Tempo - v. 1, n. 2, jul-out/2019 - p. 26-51 
(1953-7). Les sources sont disponibles sur http://chineseposters.net/, sur le site de 1'Université de Leiden. Sur cette page il y a les affiches de la collection de Stefan Landsberger, professeur émérite de cette institution. La méthode iconologique a été utilisée pour l'analyse d'images et l'Analyse Critique du Discours pour l'étude des sous-titres d'affiches. On postule que le Parti Communiste a utilisé les affiches pour construire une hégémonie dans la société chinoise sur des relations de genre considérées par rapport au socialisme, en valorisant les modèles de femmes actives dans le monde du travail et de couples harmonieux, qui ne porteraient pas leurs problèmes à la société de production. Cet aspect cause l'augmentation, un facteur qui est considéré fondamental pour la transition socialiste.

Mots-clés: Chine. Genre. Plan quinquennal. Révolution chinoise. Socialisme.

\section{LAS RELACIONES DE GÉNERO AL COMIENZO DEL SOCIALISMO CHINO: REFLEXIONES ACERCA DE LOS CARTELES DE PROPAGANDA DEL PRIMER PLAN QUINQUENAL (1953-1957)}

Resumen: Este artículo tiene como objetivo dilucidar las funciones y usos relacionados con las representaciones de género de los carteles de propaganda chino del Primer Plan Quinquenal (1953-7). Las fuentes están disponibles en el sitio http://chineseposters.net/, mantenido por la Leiden University. El sitio recoge carteles de la colección de Stefan Landsberger, profesor emérito de esta institución, y de una colección privada anónima. El método iconológico se utilizó para el análisis de imágenes y el Análisis Crítico del Discurso para el estudio de subtítulos de carteles. Se argumenta que el Partido Comunista usó los carteles para construir hegemonía en la sociedad china sobre las relaciones de género consideradas de acuerdo con el socialismo, valorando modelos de mujeres activas en el mundo laboral y parejas armoniosas, que no llevarían sus problemas a la esfera de producción, permitiendo su aumento, un factor considerado fundamental para la transición socialista.

Palabras-clave: China. Género. Plan quinquenal. Revolución China. Socialismo

\section{Introdução}

A vitória da revolução chinesa, em 1949, e o esforço de construção do socialismo na China significaram uma série de intensas mudanças naquele país, especialmente no que diz respeito às relações de gênero. No tocante ao trabalho, houve a inserção em massa das mulheres à esfera da produção, com a implementação de uma reforma agrária que distribuiu lotes de terra a despeito do gênero, além da ampliação do direito ao trabalho a todas as pessoas adultas (BEJA, 1995, p. 29-30). Já em relação aos direitos políticos e individuais, as mulheres passaram a poder votar e a escolher seu cônjuge, o pátrio poder foi extinto e a prática de enfaixamento dos pés das meninas, considerada um símbolo de beleza, foi proibida (Ibid., p. 27-28). Portanto, houve uma tentativa de ruptura com as relações tradicionais de gênero, baseadas no confucionismo, o qual estimulava o respeito às hierarquias e à harmonia social, promovendo a naturalização dos papéis femininos de mãe, esposa e filha (Ibid., p. 01-02).

No que concerne aos princípios confucionistas que estruturavam a sociedade chinesa pré-revolucionária, eles foram identificados pelos comunistas como sinônimos de atraso - traços semifeudais - e obstáculos à modernização e ao processo de 
edificação do socialismo na China, sendo imprescindível a sua superação (DABAT, 2006, p. 161-165). Logo, ao chegar ao poder, o Partido Comunista Chinês ${ }^{3}$ buscou difundir representações de gênero que iam de encontro àquelas visões, principalmente através da mobilização de cartazes de propaganda, haja vista que a China apresentava uma população com escolaridade baixíssima - em 1952, a média de anos de educação primária para pessoas acima dos quinze era de 1,7 ano (MADDISON apud MORAIS, 2011, p. 39).

Neste sentido, o intuito principal do trabalho em questão é elucidar as possíveis funções e usos relacionados às representações de gênero dos cartazes de propaganda do período do I Plano Quinquenal ${ }^{4}$ chinês, o qual vigorou entre 1953 e 1957. Além disso, procura-se articulá-las às transformações econômicas, sociais e políticas ocorridas na República Popular da China ${ }^{5}$ naqueles anos.

Os pôsteres encontram-se disponíveis no website em língua inglesa Chinese Posters $^{6}$, mantido pela Chinese Posters Foundation e pelo International Institute of Social History (IISH) da Leiden University, sediada em Amsterdã, na Holanda. Essa plataforma virtual reúne mais de sete mil pôsteres de propaganda chineses oriundos da coleção de Stefan Landsberger, professor emérito dessa instituição, e de uma coleção particular anônima. Além disso, ela abrange cartazes produzidos entre o início do século XX e o começo do XXI, organizados por assunto no menu Themes.

Em razão da base com a qual trabalha-se reunir um número muito elevado de pôsteres de propaganda, inicialmente realizou-se a filtragem do acervo por meio das seções temáticas relacionadas à questão de gênero, isto é, aquelas que contivessem no título uma das seguintes palavras-chave: “woman" (mulher), "women” (mulheres), "marriage" (casamento), "family/families" (família/famílias), "wife" (esposa), "mother" (mãe), "girl" (garota) e "lady/ladies" (dama/s). Essa busca retornou um total de doze seções. Em seguida, selecionou-se de cada uma delas somente os cartazes de propaganda que foram produzidos nos anos do recorte temporal da pesquisa, isto é, 1953-1957, e que estivessem na parte principal da seção, obtendo-se um total de 19 pôsteres.

\footnotetext{
${ }^{3}$ A partir de agora nos referiremos a essa organização pela sigla PCCh.

${ }^{4}$ Colocado em prática pelo Partido Comunista Chinês, ele consistiu em um esforço de reconstrução econômica do país, arrasado após as quase três décadas de lutas que antecederam o triunfo da revolução chinesa, em 1949. Ele foi inspirado nos planos quinquenais soviéticos do período stalinista, priorizando a indústria pesada em detrimento dos campos e centralizando as decisões políticas no aparelho estatal (BELLASEN et. al., 1977, p. 58).

${ }^{5}$ De agora em diante, simplesmente, RPC.

${ }^{6}$ Disponível em: http://chineseposters.net/. Acesso em: 19 de outubro de 2019.
} 
É importante frisar que os cartazes de propaganda analisados são compostos por uma imagem em estilo realismo socialista, isto é, o modelo artístico do socialismo real, o qual celebrava “[...] o trabalho em fábricas e em fazendas coletivas” (Burke, 2017, p. 102), e por uma pequena legenda explicativa. Por isso, optou-se por duas metodologias de análise diferentes, quais sejam: o método iconológico para o material imagético e a Análise Crítica do Discurso (ACD) para a parte escrita.

No tocante ao método iconológico (PANOFSY, 2009, p. 50-52), é importante ressaltar-se que ele consiste na identificação de três níveis de significado: o primário ou natural, referente ao material, linhas, formas e cores, de modo a perceber os fatos e expressões representadas; o secundário ou convencional, dedicado ao estabelecimento de ligações entre os motivos artísticos e assuntos e conceitos; e o mais importante, o significado intrínseco ou conteúdo, com o intuito de identificar o período, classe social, gênero etc. representados. Neste sentido, essa metodologia parte da concepção segundo a qual as obras de arte estão relacionadas ao seu contexto histórico e cultural, sendo inseparável dele. Logo, a análise aprofundada desses materiais deve, necessariamente, considerar o contexto em que foram construídos.

Já no que diz respeito à $\mathrm{ACD}$, ela constitui uma perspectiva sobre a língua e sobre a semiose (linguagem visual, corporal, dentre outras) "como um elemento ou momento do processo social material" (FAIRCLOUGH, 2012, p. 307). Em outras palavras, ela defende que a língua e as diversas modalidades de linguagens são indissociáveis das práticas sociais, isto é, das maneiras de agir na sociedade desde uma posição na estrutura social, encontrando-se relacionadas à produção da vida social, seja no âmbito econômico, político, cultural ou cotidiano (Ibid., p. 308). Neste sentido, a ACD propõe uma análise em cinco etapas (Ibid., p. 311-314), quais sejam: 1) a identificação de um problema e 2) dos empecilhos para a sua solução; 3) a análise do discurso, isto é, de sua apreciação crítica com o intuito de verificar como ele contribui para a manutenção de relações de poder e de dominação, ou seja, seu caráter ideológico; 4) o estudo das contradições do discurso e das possibilidades de mudança que ele engendra; e 5) a apreciação da eficácia desse discurso, isto é, de sua contribuição para a emancipação social e o ajuste.

\section{As "novas mulheres" da China nova}

A partir da análise do material coletado, classificou-se os pôsteres de propaganda do I Plano Quinquenal em seis categorias, quais sejam: os "casais 
harmoniosos", as "camponesas-modelo", as "operárias-modelo", as "cuidadoras", as "mulheres guerreiras" e as "mulheres unidas". Essas representações, isto é, elementos que possibilitam aos integrantes de uma determinada sociedade recorrerem a um mesmo conjunto de significados, ou seja, se sentirem parte de um mesmo grupo (CARDOSO, 2000, p. 9-10) foram empregadas pelo PCCh como forma de mostrar ao conjunto da sociedade chinesa como ela deveria ser na nova ordem revolucionária no tocante às relações de gênero. Em outras palavras, a partir de uma elaboração social do feminino e do masculino desde as diferenças anatômicas, em uma relação social, a qual se dá no "terreno do poder, onde têm lugar a exploração dos subordinados e a dominação dos explorados, dominação e exploração sendo faces de um mesmo fenômeno" (SAFFIOTI, 1992, p. 185), buscava-se indicar aos homens e às mulheres chinesas a forma correta de agirem e de se relacionarem.

Neste sentido, os pôsteres de propaganda foram utilizados pelo PCCh de modo a construir hegemonia (GRAMSCI, 1999, p. 37 e 81) na China. Por um lado, contribuíram para a elaboração de um consenso a respeito de como homens e mulheres deveriam se comportar e se relacionar, bem como de que modo as famílias deveriam ser estruturadas na transição socialista. Por outro, eram um elemento de coerção, pois determinavam o modelo correto de família e de relações de gênero. Além disso, esse processo se encontrava intrinsecamente relacionado às transformações na esfera da produção ocorridas na RPC a partir de 1949.

A seguir se debruçará sobre cada uma das categorias de representações de gênero supracitadas dos cartazes de propaganda do I Plano Quinquenal chinês.

\section{Os "casais harmoniosos"}

Incluiu-se na categoria "casais harmoniosos" os pôsteres de propaganda que representam registros ou festas de casamento, nos quais são apresentados casais de camponeses expressando grande felicidade, indicando uma forte harmonia entre eles na esfera privada. Além disso, nesses cartazes é sugerido que a ausência de conflitos no lar, decorrente da liberdade de casamento e da monogamia, determinadas pela Nova Lei do Casamento de 1950 (BEJA, 1995, p. 28-29), levariam a uma harmonia nas relações sociais na esfera da produção, sendo favorável ao seu incremento. 
Figura 1: A happy marriage, 1953 (Um casamento feliz ${ }^{7}$ )

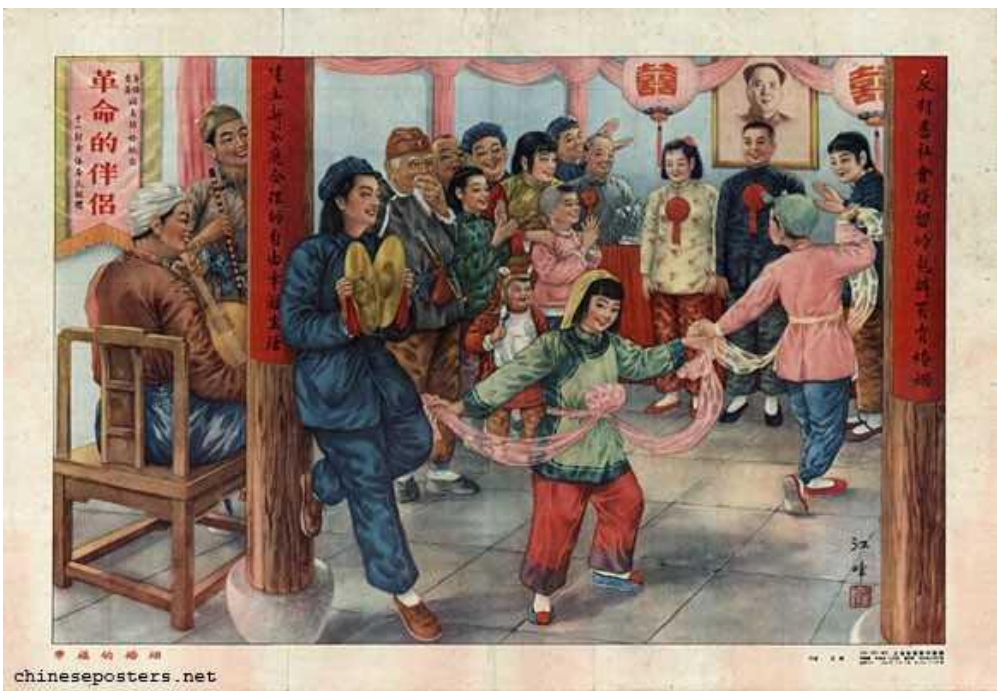

Fonte: The IISH-Landsberger Collections. Disponível em: https://chineseposters.net/posters/e15-472.php. Acesso: 22 de agosto de 2019.

Neste pôster, representa-se uma festa de casamento de camponeses. O primeiro fato é perceptível em razão de haver um homem e uma mulher jovens ao fundo da cena encostados um no outro, quase de mãos dadas, e com uma espécie de adesivo vermelho colado em seus peitos, um símbolo de que contraíram matrimônio. Atrás deles está um retrato de Mao Zedong com um olhar direcionado para a totalidade da cena. No lado esquerdo, alguns homens e mulheres, a maioria dos quais mais velhos, observam os recém-casados com expressões entusiasmadas, muito provavelmente os seus parentes. Já em primeiro plano, no lado direito, algumas meninas dançam animadamente, possivelmente as damas de honra, enquanto à esquerda vê-se uma instrumentista encostada em uma pilastra e atrás dela outros dois músicos tocando. No que diz respeito à classe, ela é identificável devido aos trajes coloridos das pessoas representadas, os quais contrastam com as cores das roupas das operárias e dos operários, de tonalidade mais escura, como cinza e azul (LANDSBERGER, 2003, p. 27), conforme se verá na seção 2.3.

É importante salientar-se a juventude do casal, a qual pode ser compreendida como uma metonímia do próprio socialismo chinês, assim como o casal, também jovem e em construção. Ademais, a felicidade demonstrada no semblante dos presentes,

\footnotetext{
${ }^{7}$ As traduções das legendas de todos os cartazes foram realizadas pelos autores.
} 
especialmente dos cônjuges, assim como a legenda do pôster, é indicativo de tratar-se de um casamento realizado a partir da livre vontade de ambos, e por isso feliz, resultado da aprovação da Nova Lei do Casamento, em 1950. Além disso, a figura onipresente de Mao Zedong, expressa no quadro atrás dos recém-casados, consiste em uma espécie de reconhecimento de que, sem ele e sua atuação no sentido de libertar a China do imperialismo e da concentração fundiária, aquela cena não seria possível.

Figura 2: Freedom of marriage, happiness and good luck, 1953 (Liberdade de casamento, felicidade e boa sorte)

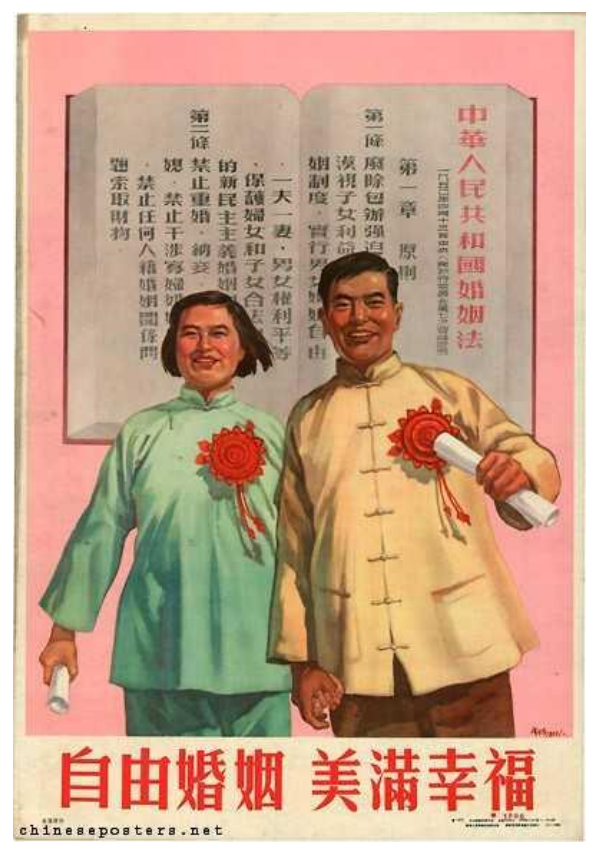

Fonte: The IISH-Landsberger Collections. Disponível em: https://chineseposters.net/posters/e15-594.php. Acesso: 22 de agosto de 2019.

Já no cartaz acima, vê-se um homem e uma mulher camponeses que acabaram de firmar matrimônio. Percebe-se isso em virtude de eles encontrarem-se de mãos dadas e com uma expressão de grande felicidade, além de ambos estarem segurando um papel enrolado, provavelmente a certidão de casamento, e de apresentarem um adesivo vermelho afixado à roupa do lado esquerdo do peito, um símbolo de que se casaram, conforme salientou-se em relação ao pôster anterior. Além disso, atrás dos cônjuges encontra-se um grande livro aberto, o qual trata-se da abertura da Nova Lei de Casamento de 1950, na qual estão os artigos que versam sobre a proibição da prática de casamentos arranjados. Em razão disso, a legenda frisa a articulação entre liberdade de casamento e felicidade, além de desejar boa sorte aos recém-casados em virtude de tratar-se, como no caso anterior, de um casal jovem. 
Figura 3: A free and independent marriage is good, there is great happiness in unified production, 1953 (Um casamento livre e independente é bom, há uma grande felicidade na produção unificada)

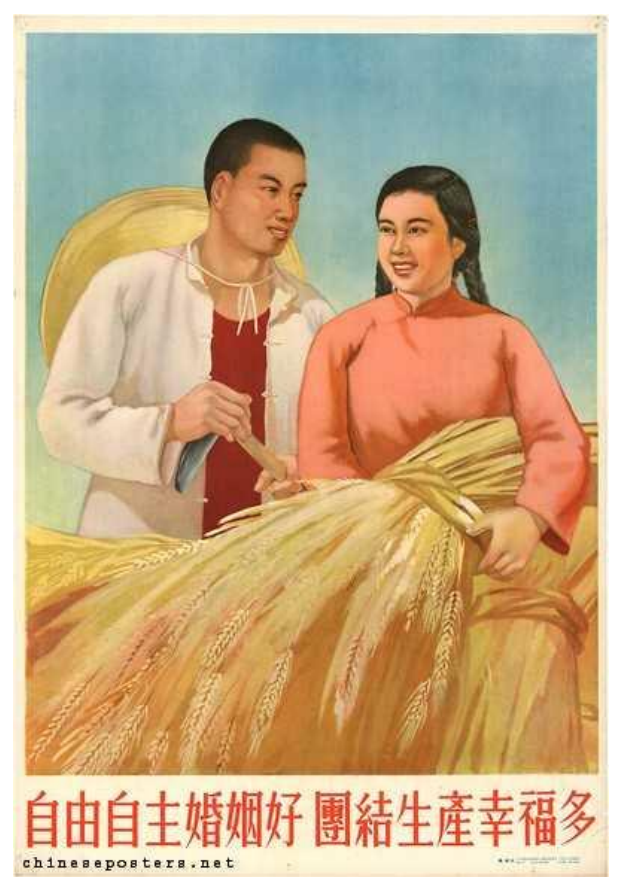

Fonte: The IISH-Landsberger Collections. Disponível em: https://chineseposters.net/posters/e15-591.php. Acesso em: 22 de agosto de 2019.

Em relação a esse pôster, trata-se mais uma vez de um casal de camponeses, haja vista que ambos estão sorrindo e olhando um para o outro com cumplicidade. Contudo, dessa vez eles são representados na esfera da produção, provavelmente realizando uma colheita, uma vez que, enquanto a mulher carrega um feixe de trigo, o homem segura uma foice nas mãos. Além disso, ambos estão com roupas leves e de mangas compridas para se proteger do sol e o camponês usa um grande chapéu de palha preso ao pescoço.

Por conseguinte, trata-se mais uma vez de um casal feliz, possibilitado pela Nova Lei do Casamento, assim como de um indicativo de que a liberdade de matrimônio viabilizaria um casal harmonioso, o qual não teria conflitos para transportar da esfera privada para a da produção, tornando possível o seu incremento, tão valorizado pelo I Plano Quinquenal (BELLASSEN, 1977, p. 57), em vigência a partir do ano de produção do cartaz em questão. Ademais, ao falar em casamento feliz em 
decorrência da liberdade de escolha, bem como de atrelar felicidade à produção, a legenda da imagem corrobora essa interpretação.

Figura 4: In marriage, keep an eve on your own interests, and return radiant after registration, 1953 (No casamento, fique de olho em seus próprios interesses e volte radiante após o registro)

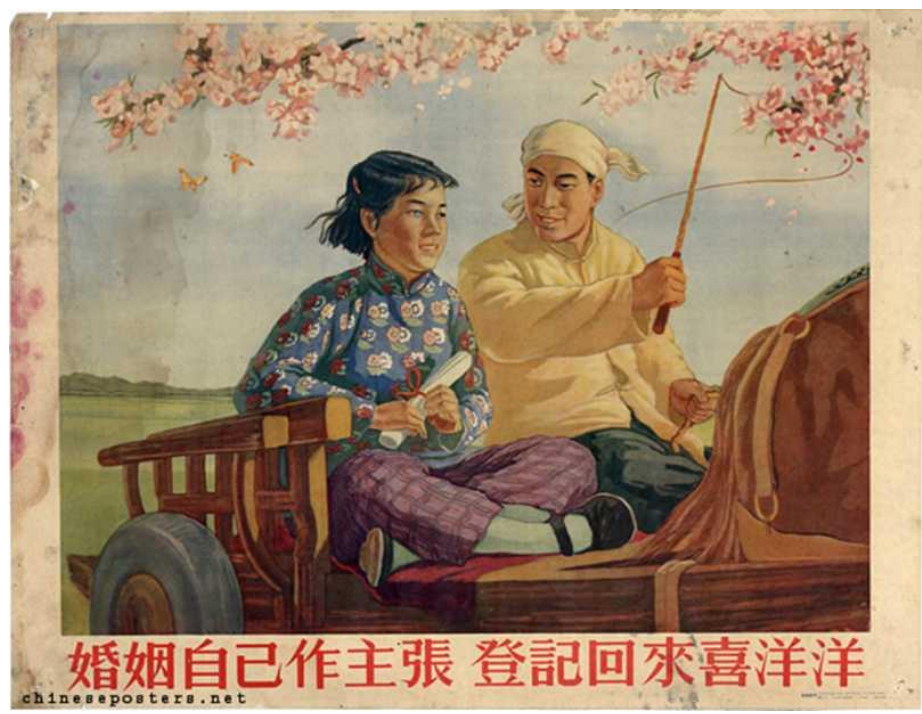

Fonte: The IISH-Landsberger Collections. Disponível em: https://chineseposters.net/posters/e15-556.php. Acesso: 22 de agosto de 2019.

No que diz respeito a esse cartaz, observa-se um casal de camponeses retornando do registro de casamento. Afirma-se isso em decorrência de ao fundo da imagem ver-se campos e montanhas e do fato dos recém-casados estarem em cima de uma carroça em movimento, sugerido pelo fato do homem empunhar um chicote para forçar o movimento de um cavalo. Além disso, eles usam roupas coloridas e a mulher segura junto ao seu peito um papel enrolado e preso por uma fita vermelha, muito possivelmente a certidão de casamento. Somado a isso, ambos estão com uma expressão contente e os galhos floridos sobre suas cabeças reforçam essa sensação de felicidade.

Ademais, é preciso ressaltar-se que o pôster em questão é direcionado muito mais às camponesas do que aos camponeses, uma vez que a legenda salienta que é preciso pensar nos próprios interesses ao firmar matrimônio, de modo a voltar feliz do registro, assim como a mulher encontra-se olhando para frente, isto é, para o futuro, com uma expressão que mescla felicidade e convicção de que ela tomou a melhor decisão. 
Figura 5: A happy marriage, a happy family, 1955 (Um casamento feliz, uma família feliz)

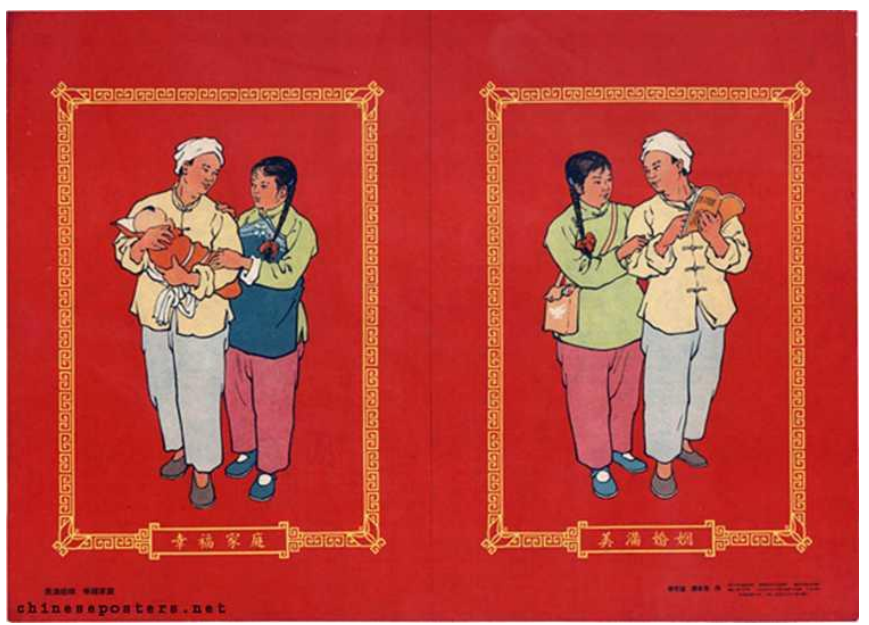

Fonte: The IISH-Landsberger Collections. Disponível em: https://chineseposters.net/posters/e15-146.php. Acesso em: 22 de agosto de 2019.

O cartaz acima apresenta um jovem casal de camponeses em duas situações diferentes, sendo que a leitura da imagem deve ser feita da direita para a esquerda, pois ela foi produzida antes da reforma da escrita chinesa, ocorrida em 1958 (LIMA, 2012, p. 32). Na primeira, o pai está com o texto da Nova Lei do Casamento (1950) em mãos e aberto em alguma passagem importante, haja vista que ele está apontando para um trecho do livro e comunicando a informação à esposa que o escuta atentamente. Na segunda, o pai segura o filho no colo enquanto a mãe encontra-se ao seu lado, atenta para que nada ocorra de errado. Em ambas as situações as expressões corporais e faciais indicam uma grande cumplicidade, felicidade e harmonia entre o casal.

O fato de o pai segurar o filho é, provavelmente, uma alusão ao fim do pátrio poder ocorrido a partir da aprovação da Nova Lei do Casamento (BEJA, 1995, p. 29) e um convite aos pais a participarem do cuidado com os filhos e dos trabalhos domésticos. Já a leitura do texto da legislação em questão feita pelo marido e comunicada à esposa indica que agora todo camponês pode se casar, pois a proibição dos casamentos arranjados também implicou na ilegalidade dos dotes, e que ele está ciente dos direitos dela e quer que ela tome conhecimento deles. Contudo, é interessante 
notarmos que o fluxo de informações é dele para ela, demonstrando que as transformações nas relações de gênero que estavam se processando naquele momento não consistiram em uma total ruptura com os padrões de gênero anteriores à revolução de 1949, mas que houve algumas continuidades e ajustamentos. Também pode ser analisado na perspectiva de um possível cuidado com os homens, para que eles não se opusessem às mudanças em curso.

\section{As "camponesas-modelo"}

$\mathrm{Na}$ categoria "camponesas-modelo" foram inseridos os cartazes de propaganda que representavam camponesas jovens e atuantes na produção de cereais e de animais para o abastecimento das cidades. Além disso, elas são retratadas com uma expressão orgulhosa do papel importante para a construção do socialismo que acreditavam estar desempenhando.

Figura 6: New view in the rural village, 1953 (Nova visão na aldeia rural)

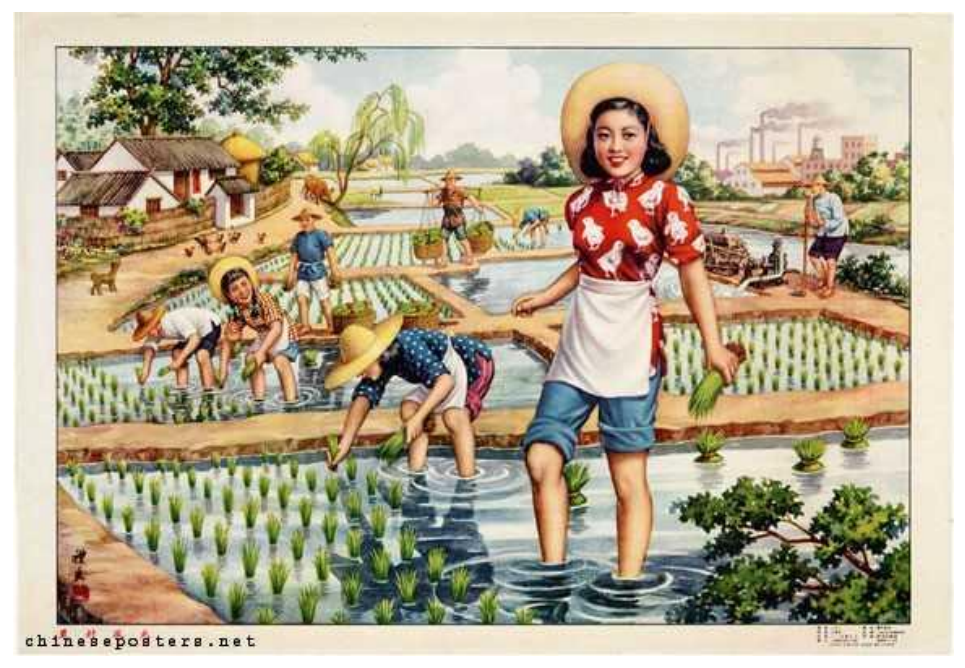

Fonte: The IISH-Landsberger Collections. Disponível em: https://chineseposters.net/posters/e12-527.php. Acesso: 22 de agosto de 2019.

No pôster em questão, encontra-se representada uma aldeia camponesa. Em primeiro plano, uma mulher jovem e sorridente está em pé e segurando uma muda de alguma variedade de arroz, haja vista que o plantio é realizado em pequenas áreas alagadas. Atrás dela, observa-se duas outras camponesas igualmente jovens inclinadas no sentido de plantarem as mudas. Apenas ao fundo aparecem alguns homens, dos quais não é possível ver sequer o rosto. Por conseguinte, é provável que se trate de habitantes de uma mesma vila camponesa cultivando cada qual o seu lote adquirido em decorrência da aprovação da Lei de Reforma Agrária de 1950 (AARÃO REIS, 1982, p. 
14-15), interpretação que é embasada pela legenda, a qual fala de uma nova visão da aldeia, buscando se referir às mudanças nos campos proporcionadas por aquela legislação. Ademais, a ênfase no trabalho feminino, faz alusão ao fato de que as terras foram distribuídas independentemente do gênero (BEJA, 1995, p. 30), assim como a participação das mulheres na produção era essencial para a construção do socialismo chinês.

Além disso, em segundo plano encontra-se a aldeia camponesa, com casas cobertas de palha e cercadas por um muro, à esquerda, e as chaminés de uma indústria, à direita, contrastando com o restante da cena. Neste sentido, a presença de uma fábrica em um cartaz sobre uma aldeia rural se deveu ao fato do I Plano Quinquenal, em vigor a partir do ano em que essa imagem foi elaborada, privilegiar a produção industrial de base e as cidades, indicando que a produção dos campos deveria alimentar a indústria (AARÃO REIS, 1982, p. 18), orientação fortemente influenciada pela assessoria técnica da União Soviética (SPENCE, 1995, p. 514).

Figura 7: The hogs of the commune must be raised to be fat and big!, 1956 (Os porcos da comuna devem ser criados para serem gordos e grandes!)

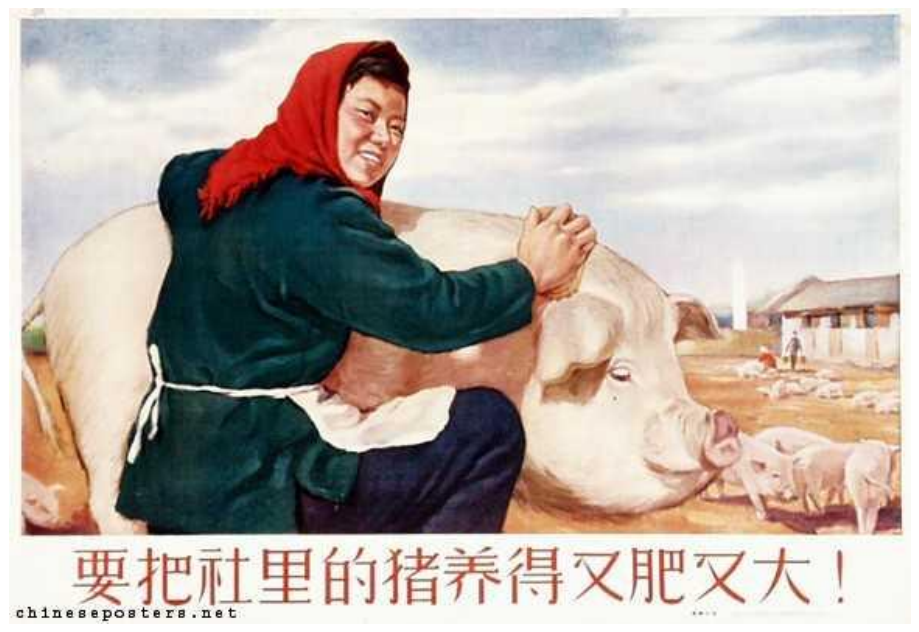

Fonte: The IISH-Landsberger Collections. Disponível em: https://chineseposters.net/posters/e15-450.php. Acesso em: 22 de agosto de 2019.

Já no que concerne à imagem acima, em primeiro plano aparece uma camponesa escovando o pelo de um grande porco e sorrindo, demonstrando estar orgulhosa de seu trabalho como criadora de suínos. Ao fundo, observa-se vários outros porcos, indicando que ela está dentro de um curral desses animais, além de outras duas pessoas trabalhando próximas à uma espécie de galpão, provavelmente no qual os porcos são trancados à noite. 
Além do mais, dessa vez a legenda aparece em tom de ordem, afirmando que os suínos precisam ser criados para serem grandes e gordos, em razão de ser necessário produzir alimentos em abundância para o abastecimento da população das cidades. Portanto, assim como no cartaz anterior, a relação subalterna dos campos em relação às cidades, na qual o trabalho supostamente emancipado das camponesas é mostrado como imprescindível, se manteve em decorrência das políticas do I Plano Quinquenal.

\section{As "operárias-modelo"}

Os cartazes dessa categoria representam operárias jovens, objetivando o estímulo à participação feminina na indústria para alavancar a produção na China, em consonância com as determinações do I Plano Quinquenal, o qual privilegiou a indústria e as cidades em detrimento dos campos.

Figura 8: We are grateful for the support of our peasant Brothers for ensuring our production!, 1956 (Somos gratos pelo apoio de nossos irmão camponeses para garantir nossa produção!)

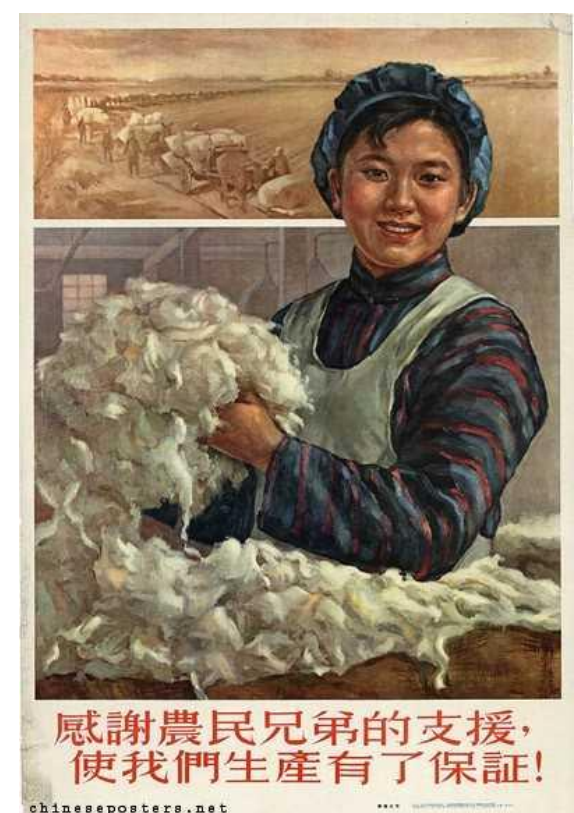

Fonte: The IISH-Landsberger Collections. Disponível em: https://chineseposters.net/posters/e15-379.php. Acesso em: 22 de agosto de 2019.

No que concerne a essa imagem, em primeiro plano é representada uma jovem operária empunhando algodão de dentro de uma saca aberta, identificável em virtude da touca e do uniforme azuis escuros que está trajando, bem como do fundo que revela um ambiente fechado e mais uma saca de algodão no canto inferior direito. Ademais, em cima e em segundo plano, observa-se uma imagem envelhecida de camponeses transportando carregamentos de algodão em carroças para a cidade. 
Logo, assim como os pôsteres anteriores que enfatizavam a importância do trabalho feminino nos campos, esse salienta a centralidade da mão-de-obra das mulheres nas fábricas para aumentar a produção industrial. Além disso, tal como as imagens da categoria anterior, ele ressalta a subordinação dos campos em relação às cidades, fulcrais no projeto do I Plano Quinquenal, conforme já se ressaltou, e que aparece na legenda como um agradecimento aos camponeses, os quais são chamados de irmãos por assegurarem a produção fabril.

Figura 9: Her achievement of glory, 1954 (Sua conquista da glória)

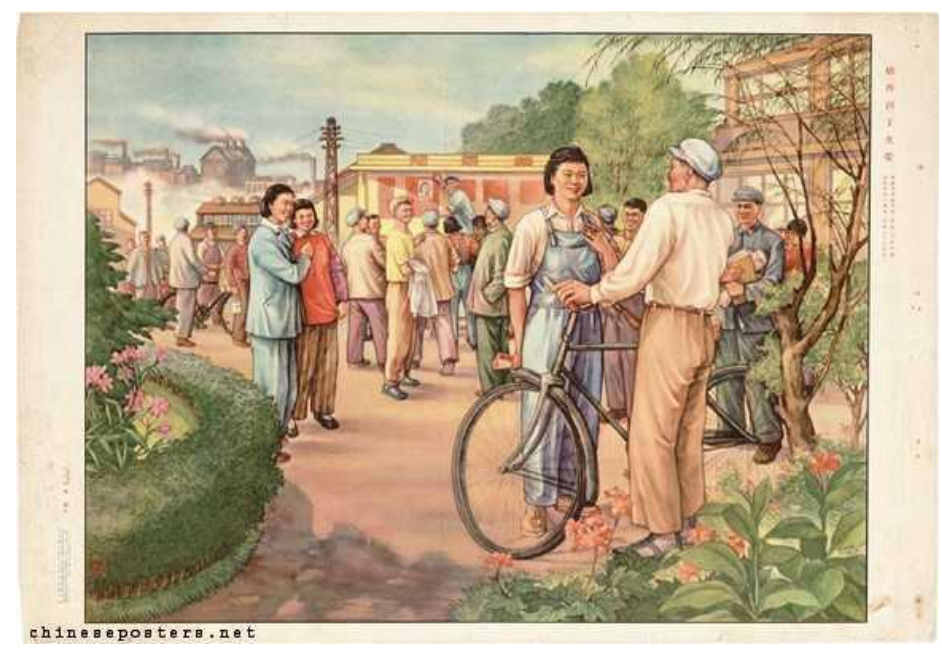

Fonte: The IISH-Landsberger Collections. Disponível em: https://chineseposters.net/themes/women.php. Acesso: 22 de agosto de 2019.

No tocante a esse cartaz, vê-se em destaque um homem mais velho presenteando com uma bicicleta uma mulher mais jovem, provavelmente sua filha, vestida com um macacão azul, uma vestimenta operária. Do lado esquerdo, uma mulher mais velha comenta algo com orgulho com uma garota que está ao seu lado enquanto ambas observam a cena, sendo possivelmente a mãe e a irmã mais nova da mulher presenteada. Do lado direito, vários homens que também parecem ser trabalhadores, talvez colegas da mulher que ganhou a bicicleta, uma vez que estão vestidos de forma parecida com a dela. Enquanto isso, ao fundo, observa-se vários operários, um deles com uma bicicleta, indo em direção às fábricas que aparecem ao fundo da imagem.

Por conseguinte, infere-se que a mulher operária está recebendo do seu pai o meio de transporte para o trabalho que está começando, haja vista os olhares orgulhosos das pessoas a sua volta. Neste sentido, esse cartaz também enfatiza a relevância da 
participação feminina no esforço de aumento da produtividade industrial nos marcos do I Plano Quinquenal, caracterizada pela legenda como a conquista da glória pelas mulheres.

Figura 10: We are proud to participate in the industrialization of the nation, 1954 (Estamos orgulhosos de participar da industrialização da nação)

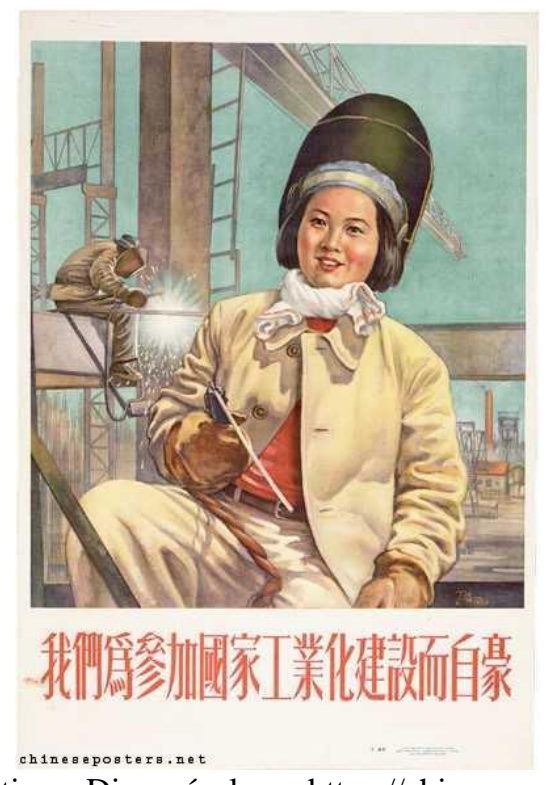

Fonte: The IISH-Landsberger Collections. Disponível em: https://chineseposters.net/posters/e16-17.php. Acesso: 22 de agosto de 2019.

Já nesta imagem, uma jovem operária sorridente do ramo da construção civil é representada durante uma pausa no trabalho de instalação da estrutura de ferro de um prédio. Atrás dela, uma pessoa de gênero não identificável, haja vista que está usando máscara, manuseia uma solda para fixar os vergalhões de metal do esqueleto do edifício.

Portanto, esse cartaz destoa dos dois anteriores, pois não mostra uma trabalhadora se dirigindo ao trabalho ou atuando na indústria têxtil, tradicionalmente um setor de predomínio do trabalho feminino (BEJA, 1995, p. 19), mas na indústria pesada. 
Ao mesmo tempo, ele também reafirma o estímulo das imagens anteriores para que as mulheres tomem parte do esforço de industrialização do I Plano Quinquenal.

\section{As "cuidadoras"}

Essa categoria se refere aos cartazes de propaganda que atrelavam os trabalhos relacionados ao cuidado das crianças e do lar às mulheres, indicando que o processo de construção do socialismo chinês não levou ao compartilhamento do trabalho doméstico e também não dissociou as tarefas relacionadas ao cuidado de uma suposta natureza feminina.

Figura 11: Growing up in happy times, 1953 (Crescendo em tempos felizes)

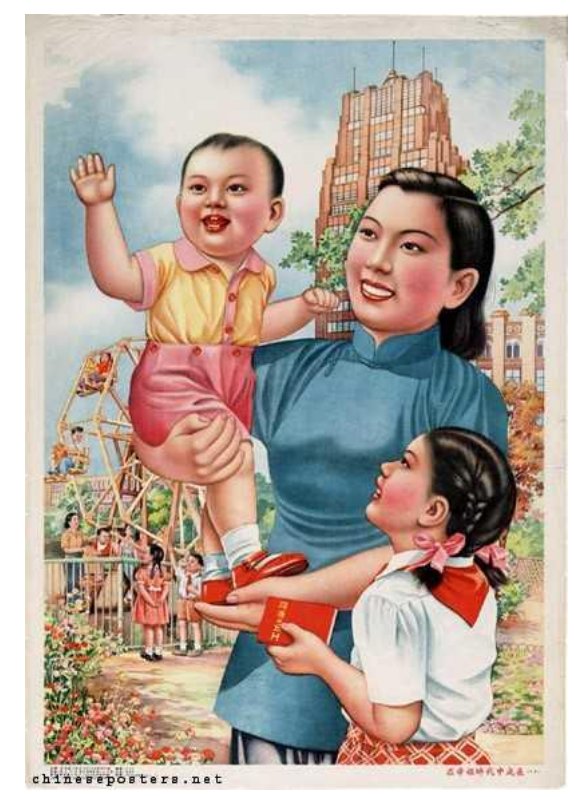

Fonte: The IISH-Landsberger Collections. Disponível em: https://chineseposters.net/posters/e16-252.php. Acesso: 22 de agosto de 2019.

No que concerne ao cartaz acima, na frente vê-se uma mulher com duas crianças, uma menina em uniforme estudantil em pé ao seu lado segurando um pequeno livro, provavelmente contendo trechos dos pensamentos de algum dirigente do PCCh, e um bebê do gênero masculino em seus braços. Os três estão sorrindo e olhando para frente e o bebê parece acenar para alguém conhecido, talvez se despedindo. Ao fundo, encontram-se várias crianças também usando uniforme escolar, brincando em uma roda gigante e sendo acompanhadas por uma mulher adulta. Em razão disso, infere-se que o 
prédio situado atrás das pessoas representadas em primeiro plano é uma escola e as crianças que estão brincando em segundo plano encontram-se no pátio da instituição. Neste sentido, entende-se que as mulheres junto às duas crianças nos dois planos da imagem são professoras. Além disso, a legenda do cartaz enfatiza que as crianças crescem felizes sob o socialismo, se referindo à possibilidade de receberem educação formal e serem ensinados por professores realmente preocupados com elas.

Portanto, observa-se nesse cartaz uma reconfiguração da condição subalterna das mulheres chinesas, haja vista que a profissão de professora das séries iniciais é atrelada ao cuidado, concebido como uma característica naturalmente feminina, tanto que nenhum homem aparece como professor.

Figura 12: Chairman Mao gives us a happy life, 1954 (Presidente Mao nos dá uma vida feliz)

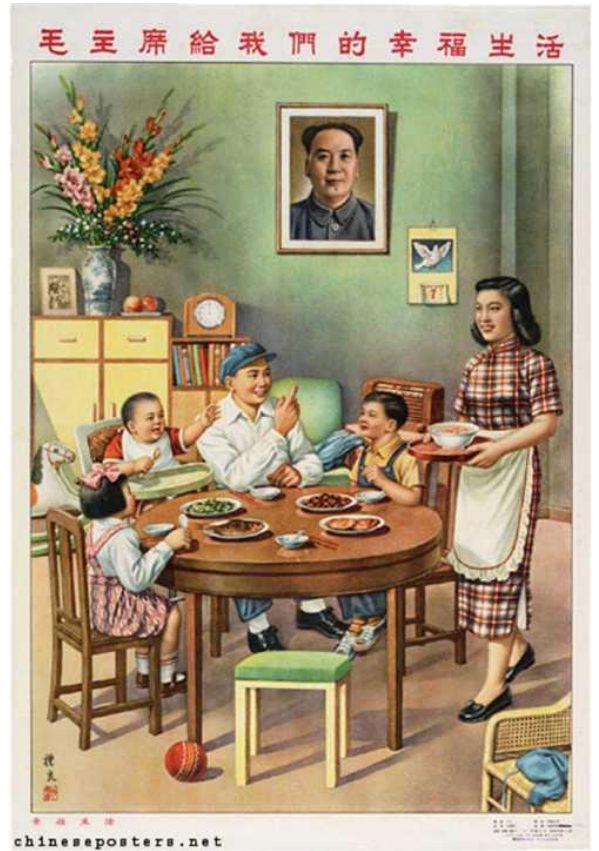

Fonte: The IISH-Landsberger Collections. Disponível em: https://chineseposters.net/posters/e16-269.php. Acesso: 22 de agosto de 2019.

Nesse pôster é representada uma família em casa durante uma refeição. Enquanto o pai está sentado à mesa brincando com os dois filhos, visivelmente mais agitados, e a filha, claramente mais contida, a mãe está em pé com uma expressão de felicidade, segurando uma tigela de alimento que leva em direção à mesa, além de vestir um avental, indicando que ela estava preparando a comida. Ao fundo, um retrato de Mao Zedong observa a cena. 
Por conseguinte, compreende-se que os trabalhos domésticos após a revolução de 1949 continuaram a ser encarados como atribuições femininas, haja vista que é a mulher representada na cena que se incumbiu de preparar e de servir a comida. Além disso, a foto de Mao atrás das personagens e a legenda do cartaz reforçam a ideia de que a revolução por ele liderada era a responsável por aquela vida de prosperidade, expressa nos alimentos em abundância sobre a mesa e na felicidade indicada pelo semblante dos membros da família.

Figura 13: Daddy goes to work, we go to school, 1954 (Papai vai para o trabalho, nós vamos para a escola)

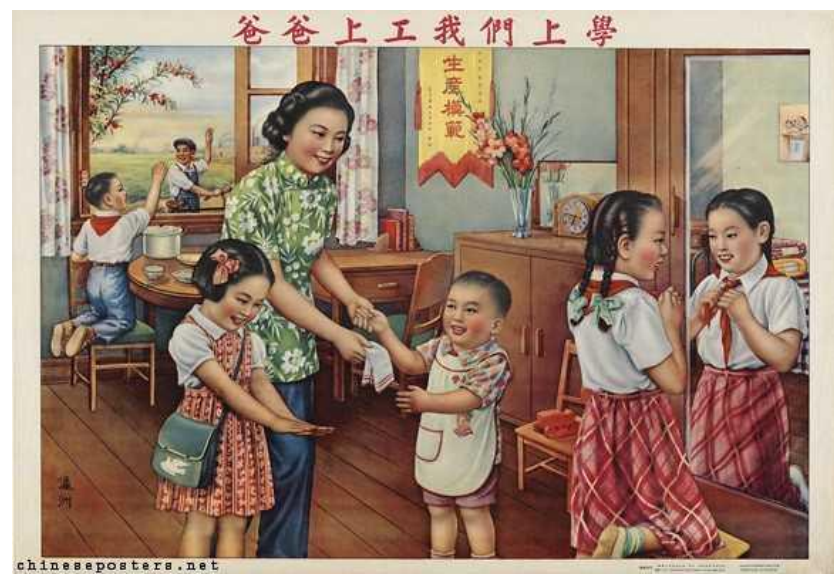

Fonte: The IISH-Landsberger Collections. Disponível em: https://chineseposters.net/posters/pc-1954005.php. Acesso: 22 de agosto de 2019.

Já na imagem acima, uma mãe está arrumando seus filhos para levá-los à escola, sendo eles uma garota mais velha que está olhando para o espelho enquanto arruma a gravata de seu uniforme, uma menina mais nova que olha para suas unhas pintadas e um pequeno garoto segurando a mão da mãe, além de um outro menino ao fundo que se despede do pai, o qual está indo de bicicleta para o trabalho na indústria. Fato que se percebe em razão de seu uniforme operário de cor azul escura e de aparecerem chaminés atrás dele. Somado a isso, a legenda do cartaz enfatiza que o pai está indo trabalhar e as crianças estudar. 
Portanto, nesse cartaz observa-se a permanência da naturalização dos cuidados com os filhos como uma atribuição feminina, uma vez que a mãe é representada como a responsável por auxiliar os filhos a vestir seu uniforme e levá-los para o colégio, enquanto o pai está indo para o trabalho.

Figura 14: A new household that is democratic, peaceful, and engages in united production, 1954 (Um novo lar que é democrático, pacífico e se engaja na produção unida)

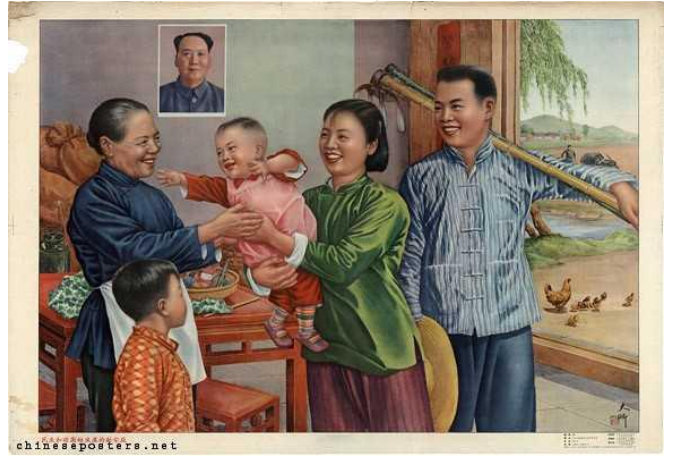

Fonte: The IISH-Landsberger Collections. Disponível em: https://chineseposters.net/posters/e15-286.php. Acesso: 22 de agosto de 2019.

No que concerne a esse pôster, pode-se observar uma família camponesa, na qual o pai e a mãe estão saindo para o trabalho, haja vista que ele carrega em seu ombro duas enchadas e segura um grande chapéu de palha, enquanto a mãe dá o bebê que estava em seu colo para uma mulher mais velha, a qual encontra-se ao lado do filho mais velho do casal. Provavelmente, a anciã é a sogra da jovem, fato identificável em razão do casamento camponês na China ser exogâmico e virilocal, isto é, as mulheres costumavam se casar com homens de fora de sua aldeia e iam morar na casa do marido (Beja, 1995, p. 31). Ao fundo, aparece o retrato de Mao olhando para a cena.

Por conseguinte, nessa imagem observa-se que ao mesmo tempo que as mulheres mais jovens eram estimuladas à participar da produção ao lado dos homens, daí a legenda falar em produção unida, o trabalho doméstico não foi compartilhado com o cônjuge, mas deslocado para outras mulheres, como sogra. Além disso, o fato do retrato de Mao encontrar-se ao fundo sugere que aquele lar supostamente igualitário e harmonioso era resultado direto das ações dessa liderança do PCCh.

\section{As "mulheres guerreiras"}

Nesta categoria, classificou-se os cartazes que diziam respeito à representação de mulheres enquanto soldados, ressaltando que o socialismo chinês havia possibilitado a 
elas adentrarem em setores da vida social outrora exclusivos ao homens, como as forças armadas.

Figura 15: Study the battle spirit of the Red Army during the Long March, conquer nature, build up our nation, 1953 (Estude o espírito de batalha do Exército Vermelho durante a Longa Marcha, conquiste a natureza, construa a nação)

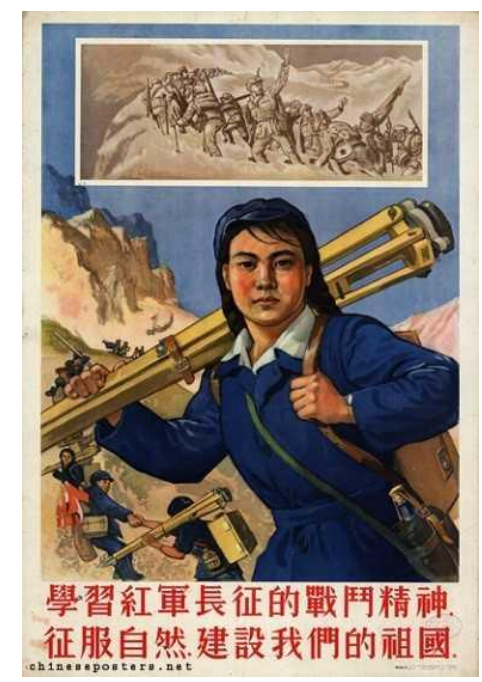

Fonte: The IISH-Landsberger Collections. Disponível em: https://chineseposters.net/posters/e15-832.php. Acesso: 22de agosto de 2019.

No que tange ao cartaz acima, ele representa em primeiro plano uma jovem participando da Longa Marcha, ocorrida entre 1934 e 1935, na qual os comunistas se deslocaram a pé do sudeste chinês para o noroeste do país, numa tentativa de fugir da repressão das tropas do Guomindang, sendo o Exército Vermelho, ao qual a legenda se refere, o braço armado do PCCh (CHESNEAUX; LE BARBIER, 1975, p. 123-127).

Neste sentido, o cartaz busca passar a mensagem segundo a qual as mulheres chinesas do começo dos anos 1950 deveriam se inspirar no exemplo e na convicção de luta contra as adversidades naturais daquelas que participaram do feito heroico da Longa Marcha, de modo a participarem ativamente da produção, ou seja, dominando a natureza, e contribuindo para a construção do socialismo, isto é, da nação, conforme expresso na legenda. Portanto, constituindo-se em uma espécie de "guerreiras".

Além disso, é possível que o pôster faça referência à divisão que ocorreu no movimento de mulheres chinesas nos anos 1950, da qual resultaram duas frações. De um lado, encontrava-se o grupo que defendia que homens e mulheres poderiam ter direitos iguais e exercer as mesmas funções, mas ainda assim continuariam a ser diferentes por conta de apresentarem distinções anatômicas intransponíveis. De outro, estavam as adeptas da concepção de que essas diferenças supostamente naturais 
poderiam ser superadas, daí a legenda mencionar a conquista da natureza (MANNING, 2011).

Figura 16: New China's female parachuters, 1955 (Paraquedistas do sexo feminino da nova China)

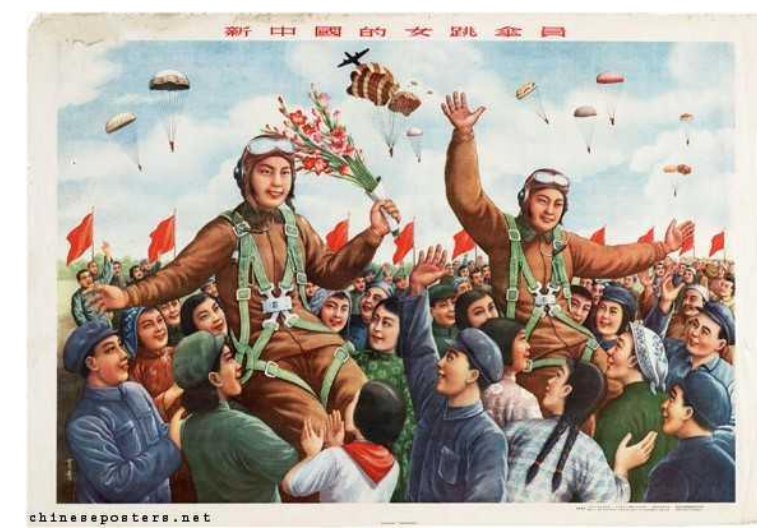

Fonte: The IISH-Landsberger Collections. Disponível em: https://chineseposters.net/posters/e15-27.php. Acesso: 22 de agosto de 2019.

Já nesse cartaz, representou-se duas mulheres paraquedistas, ou seja, de fato "guerreiras". Na imagem, elas aparecem em primeiro plano sendo carregadas pelo povo após um salto bem-sucedido, enquanto ao fundo encontram-se diversos outros paraquedistas cujo gênero não é identificável por estarem no ar, imediatamente após um salto do avião que os sobrevoa. Além disso, o público presente carrega diversas bandeiras da China socialista, a "nova China" mencionada nas legendas, a qual havia tornado possível o acesso feminino às forças armadas. Também é possível observar algumas crianças, incluindo meninas, que olham para as paraquedistas como um exemplo, talvez sonhando em se tornar uma delas quando crescerem.

Logo, no pôster em questão, percebemos uma clara ruptura com relação ao período anterior à revolução de 1949 , no qual os papéis femininos estavam ligados ao âmbito privado, haja vista que eram consideradas como naturalmente aptas aos afazeres domésticos e ao cuidado das crianças (BEJA, 1995, p. 03).

Figura 17: Parachuters, early 1950s (Paraquedistas, início dos anos 1950) 


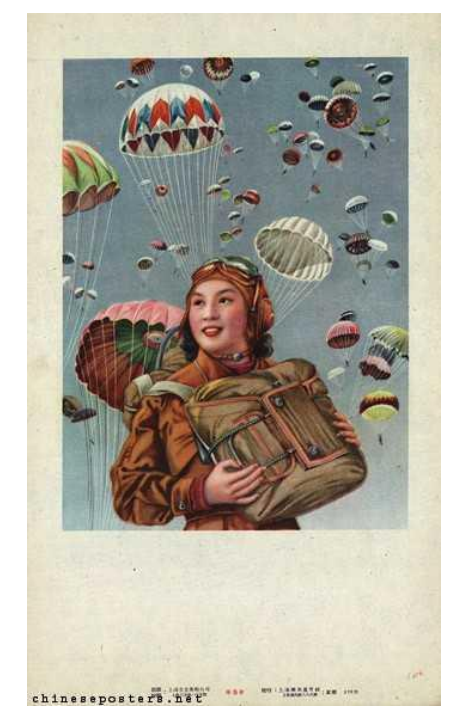

Fonte: The IISH-Landsberger Collections. Disponível em: https://chineseposters.net/posters/d25-202.php. Acesso: 22 de agosto de 2019.

De modo semelhante, no pôster acima pode-se ver uma paraquedista em pleno ar, realizando um salto, com vários outros paraquedistas de gênero impossível de ser definido ao fundo. Ela não demonstra medo, apesar da situação, apresentando um semblante que mistura felicidade e orgulho. Por conseguinte, assim como a imagem anterior, esse pôster constituía uma forma de estímulo à participação das mulheres chinesas nas forças armadas e para que os trabalhadores superassem seus desafios e limites no cotidiano, expressando uma modificaçao significativa na forma como a China concebia as relações de gênero.

Figura 18: The New China has given women the opportunity of serving the nation boundlessly and liberally! (A Nova China deu às mulheres a oportunidade de servir a nação sem limites e liberalmente!)

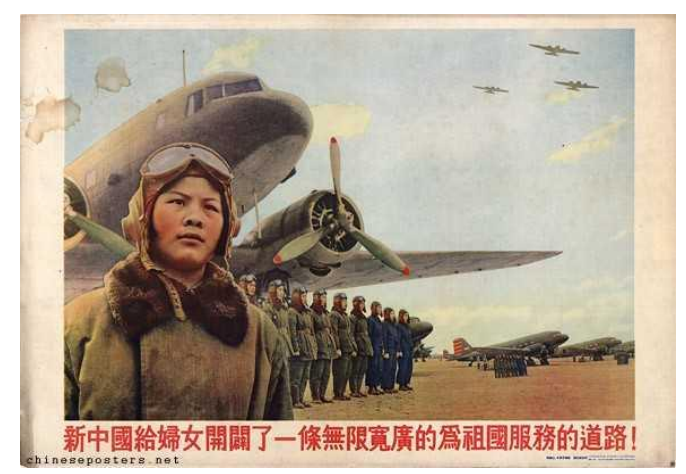


Fonte: The IISH-Landsberger Collections. Disponível em: https://chineseposters.net/posters/e15-945.php. Acesso: 22 de agosto de 2019.

Seguindo a linha das duas anteriores, essa imagem representa uma mulher paraquedista com um semblante sério, transmitindo ao observador profissionalismo, à frente de várias paraquedistas ordenadas em uma fileira, atrás das quais encontram-se quatro aviões também enfileirados, indicando que elas estão se preparando para realizar um salto. Além disso, a ideia de que a China socialista propiciou às mulheres a entrada em áreas outrora majoritariamente masculinas, como a aeronáutica, é reforçada pela legenda, a qual frisa que a Nova China possibilitou a elas servirem à nação sem obstáculos e de forma livre.

\section{As "mulheres unidas"}

Figura 19: We have been pregnant with life, we want to safeguard life!, 1957 (Nós estivemos grávidas da vida, queremos salvaguardar a vida!)

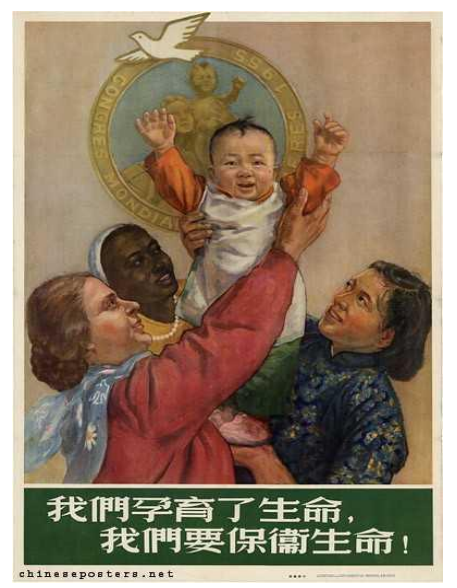

Fonte: The IISH-Landsberger Collections. Disponível em: https://chineseposters.net/posters/e15-353.php. Acesso em: 22 de agosto de 2019.

Por fim, vale ressaltar que não foi possível enquadrar um dos cartazes do I Plano Quinquenal nas categorias supracitadas, sendo necessário inseri-lo em uma classificação à parte, a qual chamou-se de "união das mulheres". Nele, são representadas uma mulher chinesa, uma negra e uma russa empunhando juntas um bebê, aludindo à vida, a qual é supostamente originária do ventre feminino, como ressalta a legenda e, em razão disso, ninguém mais capacitado do que elas para a defenderem. Além disso, acima da cabeça do bebê voa uma pomba branca, uma clássica representação da liberdade. Também é preciso ressaltar a existência de um brasão dourado no fundo da cena, no qual está cunhada a inscrição "Congresso Mundial de Mulheres de 1955".

Logo, esse cartaz ressalta a força das mulheres socialistas e do terceiro mundo, no sentido de lutar pela paz mundial, mas reforça um estereótipo de gênero, uma vez 
que considera a maternidade como algo que faz parte da natureza feminina, além de afirmar que isso as tornaria mais sensíveis à proteção da vida.

\section{Conclusões}

Ao longo deste artigo, foram analisadas as representações de gênero dos cartazes de propaganda chineses produzidos durante a vigência do I Plano Quinquenal (19531957), buscando descrever as imagens de forma densa e relacionar suas caraterísticas às transformações pelas quais a China passou naqueles anos. Neste sentido, classificou-se os pôsteres nas categorias "casais harmoniosos", "camponesas-modelo", “operáriasmodelo", "cuidadoras", "mulheres guerreiras" e "união das mulheres".

No tocante à classe dos "casais harmoniosos", observou-se que os pôsteres nela incluídos faziam alusão aos casamentos de camponeses realizados a partir da livre escolha dos cônjuges, possibilitada pela Nova Lei do Casamento. Além disso, eles buscavam articular a liberdade de matrimônio com a harmonia no âmbito privado, fator compreendido como benéfico à produção, uma vez que não haveria conflitos para serem transportados do lar para o trabalho. Em relação à categoria "camponesas-modelo", ela foi formada a partir de cartazes que enfatizavam a atuação de mulheres na agricultura e na pecuária como sinônimo de sua emancipação, visando estimular a participação da parcela feminina do campesinato na ampliação dos gêneros alimentícios para o abastecimento das cidades. Já a das "operárias-modelo" abarcou as imagens de mulheres trabalhando nas indústrias, as quais tinham o intuito de persuadi-las a tomar parte no esforço de ampliação da produção fabril engendrado pelo I Plano Quinquenal.

No que diz respeito à classe das "cuidadoras", ela abrangeu as representações que atrelavam o trabalho doméstico e de cuidado das crianças às mulheres, indicando uma permanência em relação aos papéis de gênero anteriores à revolução chinesa. No que concerne à categoria "mulheres guerreiras", ela incluiu os pôsteres que retratavam as mulheres como soldados, estimulando a participação feminina nas forças armadas e ressaltando que a China socialista havia possibilitado a elas atuarem em setores tradicionalmente masculinos.

Finalmente, não foi possível encaixar um dos cartazes de propaganda nas categorias supracitadas, sendo necessário classificá-lo como "união das mulheres". Nele, são mostradas uma mulher chinesa, uma russa e uma negra que por meio do somatório de suas forças conseguiriam defender a vida, em razão de serem capazes de gerá-la, em um evidente reforço da concepção de uma suposta essência feminina. 
Portanto, nos anos de implementação do I Plano Quinquenal, o PCCh utilizou largamente os pôsteres de propaganda para forjar uma hegemonia na sociedade chinesa a respeito das relações de gênero e do padrão de família considerados em acordo com a nova ordem revolucionária, promovendo várias rupturas em relação aos valores confucionistas que norteavam a China antes de 1949, mas também reproduzindo diversos papéis tradicionais de gênero. Por um lado, foram valorizadas representações de mulheres ativas na esfera da produção e de famílias harmoniosas, formadas a partir da livre vontade dos cônjuges. Por outro, os trabalhos domésticos e o cuidado dos filhos continuaram a ser considerados atribuições naturais das mulheres.

\section{Referências}

AARÃO REIS, Daniel. A construção do socialismo na China. São Paulo: Brasiliense, 1982.

BEJA, Flora Botton. La larga marcha hacia la igualdad. Mujer y familia en China. In: FISAC, Taciana (org.). Mujeres en China. Madri: Agencia Española de Cooperación Internacional, 1995.

BELLASSEN, J. et al. Histoire de Chine 4: un nouveau communisme, 1949-1976. De la Libération à la mort de Mao Zedong. Paris: Hatier, 1977.

BURKE, Peter. Testemunha ocular: o uso de imagens como evidência história. São Paulo: Editora Unesp, 2017.

CARDOSO, Ciro Flamarion. Introdução: uma opinião sobre as representações sociais. In: CARDOSO, Ciro Flamarion; MALERBA, Jurandir (orgs.). Representações: Contribuição a um debate transdisciplinar. Campinas: Papirus, 2000.

CHESNEAUX, Jean; LE BARBIER, Françoise. Histoire de la Chine 3: la marche de la révolution, 1921-1949. De la fondation du parti communiste à la Liberation. Paris: Hatier Université, 1975.

DABAT, Christine Rufino. Mulheres no movimento revolucionário chinês (18391949). Recife: Ed. Universitária da UFPE, 2006. (Livro-texto, v. 3)

FAIRCLOUGH, Norman. Análise crítica do discurso como método em pesquisa social científica. Linha d'Água, São Paulo, v. 2, n. 25, p. 307- 329, 2012.

GRAMSCI, Antonio. Cuaderno 13 (XXX) 1932-1934: notas breves sobre la política de Maquiavelo. In: GERRATANA, Valentino (org.). Cuadernos de la cárcel: Tomo 5. México, D.F.; Puebla: Ediciones Era; Benemérita Universidad de Puebla, 1999.

LANDSBERGER, Stefan. Ascensão e queda do cartaz de propaganda chinês. In: DUO, Duo; LANDSBERGER, Stefan; MIN, Anchee. Chinese propaganda posters: From the collection of Michel Wolf: Köln: Taschen, 2003. 
LIMA, Ligia Wey Neves. O ensino de mandarim no Brasil: um estudo comparativo entre os sistemas pinyin e zhuyin fuhao. Dissertação (Mestrado em Linguagem e Educação) - Programa de Pós-Graduação em Linguagem e Educação, Faculdade de Educação, Universidade de São Paulo, São Paulo, 2012.

MANNING, Kimberley Ens. The gendered politics of woman-work: rethinking radicalism in the Great Leap Forward. In: MANNING, Kimberley Ens; WEMHEUER, Felix (Orgs.). Eating bitterness: new perspectives on China's Great Leap Forward and famine. Vancouver: UBC Press, 2011.

MORAIS, Isabela Nogueira de. Desenvolvimento econômico, distribuição de renda e pobreza na China contemporânea. Tese (Doutorado em Economia) - Programa de PósGraduação em Economia, Instituto de Economia, Universidade Federal do Rio de Janeiro, Rio de Janeiro, 2011.

PANOFSKY, Erwin. Iconografia e iconologia: uma introdução ao estudo da arte da Renascença. In: PANOFSKY, Erwin. Significado nas artes visuais. São Paulo: Perspectiva, 2009.

SAFFIOTI, Heleieth. Rearticulando gênero e classe social. In: BRUSCHINI, Cristina; COSTA, Albertina de Oliveira (orgs.). Uma questão de gênero. Rio de Janeiro: Rosa dos Tempos; São Paulo: Fundação Carlos Chagas, 1992.

SPENCE, Jonathan. Em busca da China moderna: quatro séculos de história. São Paulo: Companhia das Letras, 1995. 